\title{
Quantitation of monoclonal plasma cells in bone marrow biopsies in plasma cell dyscrasia
}

\author{
G.M. Markey ${ }^{\mathrm{a}, *}$, P. Kettle ${ }^{\mathrm{a}}$, T.C.M. Morris ${ }^{\mathrm{a}}$, N. Connolly ${ }^{\mathrm{a}}$ and H. Foster ${ }^{\mathrm{b}}$ \\ ${ }^{a}$ Haematology Department, Belfast City Hospital, Belfast, BT9 7AB, UK \\ ${ }^{\mathrm{b}}$ Histopathology Department, Belfast City Hospital, Belfast, BT9 7AB, UK
}

\begin{abstract}
Direct measurement of monoclonal plasma cell mass in bone marrow biopsies may be a useful parameter to establish in plasma cell dyscrasia. In this study monoclonal plasma cells $/ \mathrm{mm}^{2}$ in light chain immunoglobulin immunostained archival bone marrow sections from 22 patients in whom a diagnosis of multiple myeloma (MM) had been excluded but who had monoclonal proteins were counted by two observers at light microscopic level. There was good correlation between the counts of the two observers. The levels of monoclonal plasma cells $/ \mathrm{mm}^{2}$ in biopsies were not related to the $\%$ counts in the aspirates taken at the same time as the biopsies. Three of seven patients with biopsy levels in excess of the polyclonal levels in patients without plasma cell dyscrasia developed progressive MM within the observation time. Monoclonal plasma cell levels $/ \mathrm{mm}^{2}$ of bone marrow biopsies can be measured and they provide a useful parameter for the assessment of patients with low volume plasma cell dyscrasia. Colour figure can be viewed on http://www.esacp.org/acp/2003/25-4/markey.htm
\end{abstract}

Keywords: Bone marrow biopsy, light chain immunoglobulin, plasma cell dyscrasia, tumour quantitation, immunocytochemistry

\section{Introduction}

Bone marrow biopsies are frequently submitted for examination in order to confirm or exclude the diagnosis of multiple myeloma or other plasma cell dyscrasia. The diagnosis of myeloma may be possible where there is sheeting of or 'very large' numbers of plasma cells but when there are 'increased', 'moderate', or 'small' numbers of plasma cells present it can be difficult to formulate a realistic and helpful opinion. Measurement of the absolute numbers of monoclonal plasma cells $\mathrm{mm}^{2}$ of bone marrow would provide a parameter, which would be more satisfactory than 'large', 'moderate' or 'small' increases of plasma cells.

Morphometric analysis of tumour bulk in Giemsa stained sections of formalin fixed bone marrow trephines from patients with an established diagnosis of MM using a Zeiss integrating eyepiece has been shown

\footnotetext{
*Corresponding author: Dr G.M. Markey, Associate Specialist, Haematology Department, C Floor, Belfast City Hospital, Lisburn Road, Belfast, BT9 7AD, UK. Tel.: 02890 329241, Ext. 2768; Fax: 02890 263870; E-mail: geraldine.markey@ bll.n-i.nhs.uk.
}

to be possible $[1,2]$ and to correlate with clinical stage of disease [1]. Results were established as volumes of disease $\%$. This technology is not routinely available, is time consuming and perhaps for these reasons has not been taken up in routine practice. A simpler process might be useful.

In this study we set out to measure, without using specialised equipment, the monoclonal plasma cell content $/ \mathrm{mm}^{2}$ of trephine biopsies from patients with monoclonal gammopathies who did not fulfil current diagnostic criteria for diagnosis of multiple myeloma. Such patients develop MM at a rate of 2-3\% per annum and any help in identifying patients likely to progress in the near future could result in their closer monitoring while others could perhaps be reviewed less frequently. If by providing absolute monoclonal plasma cell levels a group of patients showing earlier progression to MM were defined this would show that the counts obtained were meaningful and that the process might be usefully incorporated into the examination and reporting of bone marrow biopsies. 


\section{Patients, materials and methods}

Patients ( $n=22$ ) who had monoclonal serum or urinary proteins and had diagnoses of monoclonal gammopathy of uncertain significance (MGUS) $n=16$, light chain amyloidosis - AL, $n=3$, AA amyloidosis, $n=1$ or monoclonal immunoglobulin deposition disease - MIDD, $n=2$ (grouped together in this paper as non-myelomatous paraproteinaemia or NMP) made prior to 1994 were randomly identified from Haematology Department files. The diagnoses in the NMP group and exclusion of MM had been made on combined clinical radiological and laboratory evidence in accordance with established recommendations [3]. In 15 patients increased numbers of plasma cells had not been noted in H\&E stained sections of their biopsies.

$3 \mu \mathrm{m}$ sections were cut from their Bouin's fixed paraffin embedded bone marrow trephine biopsies taken at diagnosis and immunostained with anti-light chain immunoglobulin antisera using the avidin-biotin immunohistochemical technique. Polyclonal antibodies (DAKO Ltd, UK) anti- $\kappa$ (Catalogue number A 0191) and anti- $\lambda$ antisera (A 0193) were used at dilutions of $1 / 1000$ and $1 / 4000$ respectively. The optimum dilutions had been previously determined by serial dilution and immunostaining of sections from biopsies of patients with multiple myeloma of known light chain immunoglobulin restriction; sections from the latter were included as controls in the current study. The immunostained sections were examined using a $25 \times$ objective and $10 \times$ eyepiece (final magnification of $310 \times$ ). The field of vision was $0.26 \mathrm{~mm}^{2}$ and the immunostained plasma cells were rapidly counted in 4 representative fields. A second observer counted 10 fields of $0.07 \mathrm{~mm}^{2}$ at a magnification of 625 and the results were compared with those of the first observer.

The monoclonal plasma cell content $/ \mathrm{mm}^{2}$ of each biopsy was compared with the \% of plasma cells recorded in the corresponding corresponding Wright stained bone marrow aspirates (500 cell counts) and with the total polyclonal ( $\kappa+$ ve plus $\lambda+$ ve) plasma cell content from a previous study of bone marrow biopsies from patients with disorders unrelated to plasma cell dyscrasia (Unrelated disease - UD) [4].

Spearman's rank correlation coefficient was used to compare \% with absolute plasma cell levels and, the absolute plasma cells $/ \mathrm{mm}^{2}$ obtained by the two observers, the Mann Whitney test for comparison of paraprotein levels.

Evidence for progression of their plasma cell dyscrasia to MM was subsequently sought through examination of patients' charts.

\section{Results}

Colour figure can be viewed on http://www.esacp. org/acp/2003/25-4/markey.htm.

A monoclonal population was considered to be present when the ratio of $\kappa+$ ve to $\lambda+$ ve plasma cells $/ \mathrm{mm}^{2}$ fell outside $3.5 \kappa / 1 \lambda$ or $1 \kappa / / 2 \lambda$. Monoclonal plasma cell populations with diffuse distribution were demonstrated in the biopsies of 19/22 patients - in 12 of the 19, increases of plasma cells had not been noted in H\&E stained sections. The monoclonal plasma cell levels of these 19 patients are shown in Fig. 1 together with relevant clinical data from the time of presentation. The total plasma cell i.e. $\kappa+$ ve plus $\lambda+$ ve content found in a previous study [4] of bone marrow biopsies from 21 patients with UD is shown for comparison. The upper limit of total plasma cells in the latter cohort was $305 / \mathrm{mm}^{2}$. Seven patients in the current cohort had monoclonal plasma cell content in excess of this. Three of these seven patients developed evidence of progressive $\mathrm{MM}$ while none of the 12 patients with less than $305 / \mathrm{mm}^{2}$ or the three without demonstrable monoclonal populations did so after a similar length of observation.

The correlation of the absolute counts $/ \mathrm{mm}^{2}$ shown in Fig. 1 with the counts of the second observer was $0.827(p<0.001)$. Six of the seven patients with highest counts, including all three, who progressed, were similarly identified by the second observer.

Of the three patients without monoclonal populations one with a $\kappa / \lambda$ ratio of $3.4 / 1$ was discovered to have a plasmacytoma in a deeper section so had nodular disease. The other two had serum $\operatorname{IgG} \kappa$ monoclonal bands of 3 and $4 \mathrm{~g} / \mathrm{l}$ and $\kappa / \lambda$ ratio of $1.2 / 1$ and $2 / 1$, respectively.

There was no correlation between absolute monoclonal plasma cells $/ \mathrm{mm}^{2}$ in bone-marrow biopsies and $\%$ plasma cells in bone-marrow aspirates. Figure 2 demonstrates the wide variation in absolute plasma cell content - 130 and $906 / \mathrm{mm}^{2}$ - in two patients each with 9\% plasma cells in their aspirates.

There was no significant difference between paraprotein levels of the patients with monoclonal plasma cells $>305 / \mathrm{mm}^{2}$ (range, trace $-14 \mathrm{~g} / \mathrm{l}$, median $9 \mathrm{~g} / \mathrm{l}$ ) and those with $<305 / \mathrm{mm}^{2}$ (range, trace $-16 \mathrm{~g} / \mathrm{l}$, median $8 \mathrm{~g} / \mathrm{l})$.

\section{Discussion}

Bone marrow biopsies are particularly appropriate for morphometric studies because the presence of bony 


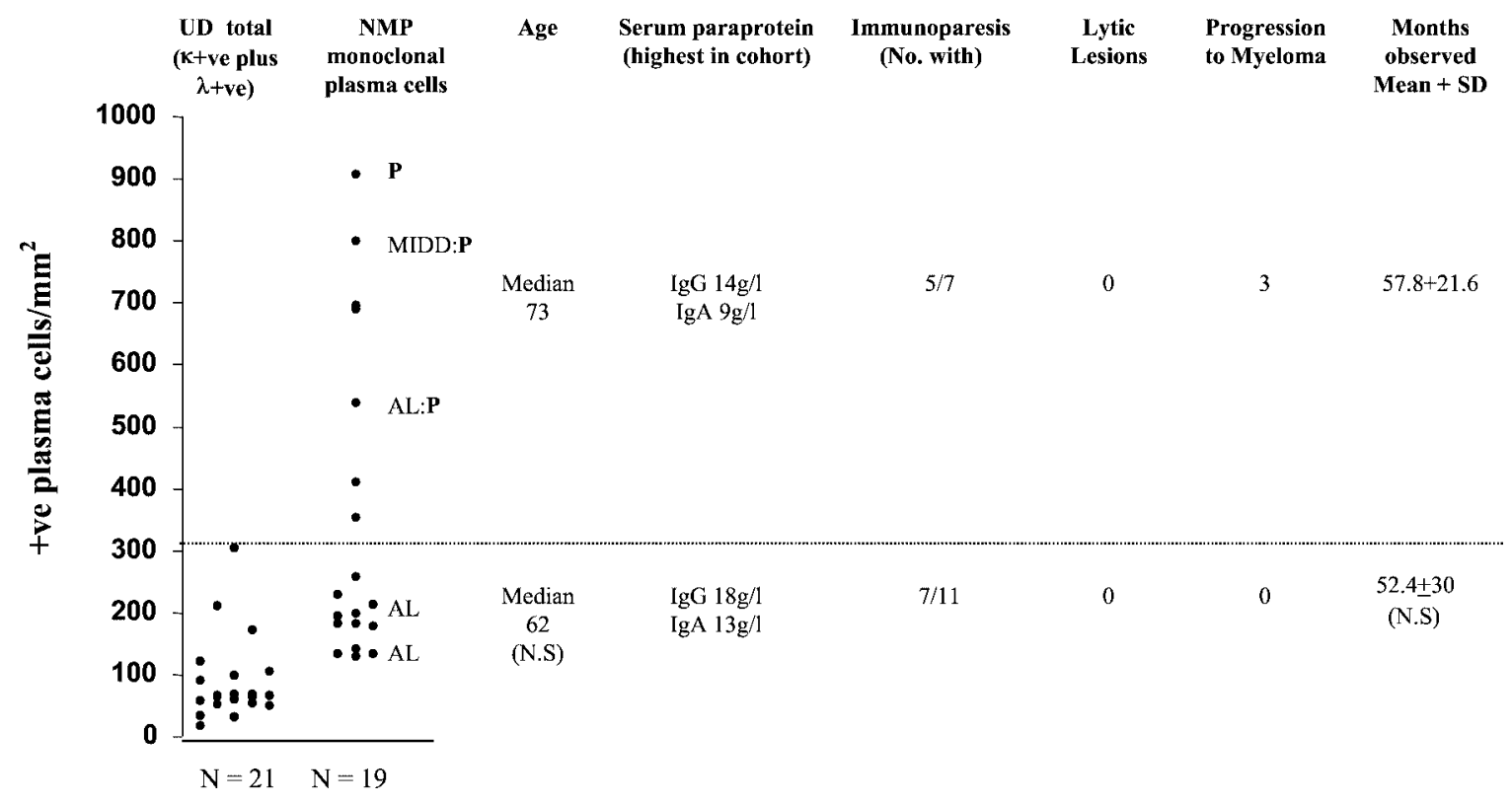

Fig. 1. Findings at presentation and outcome of 19 patients with monoclonal plasma cells above and below $305 / \mathrm{mm}^{2}$ in bone marrow biopsies from NMP patients. Also shown are total plasma cells ( $\kappa+$ ve plus $\lambda+v e)$ in 21 UD patients [4]. P, progression to MM: NS, not significant.

trabeculae precludes shrinkage effects. The field of vision for each objective of any microscope is easily calculated and the use of light chain immunoglobulin stained sections permits immunostained cells to be easily identified and counted in addition to establishing monoclonality when present.

Complete accuracy of plasma cell counting in biopsy sections is never going to be possible and variation of plasma cell content between fields occurs in plasma cell dyscrasia. Nevertheless in patients considered to have NMP enumeration of monoclonal plasma cells identified a cohort with monoclonal plasma cells $>305 / \mathrm{mm}^{2}$ and $3 / 7$ patients in this cohort were observed to develop progressive MM, the length of follow-up not differing significantly from that of the group with $<305 / \mathrm{mm}^{2}$. The upper limit of total $(\kappa+\mathrm{ve}$ and $\lambda+v e$ ) plasma cells in UD biopsies was arbitrarily chosen as the level to separate and compare the two cohorts in the absence of any other logical starting point. The results suggest that the level of $>300$ monoclonal plasma cells $/ \mathrm{mm}^{2}$ may be a reasonable criterion for diagnosis of MM in trephine biopsies. Correlation with clinical findings would then differentiate between smoldering, indolent and progressive MM. We suggest that the proposed 'cut off' level of 300 monoclonal plasma cells $/ \mathrm{mm}^{2}$ should be validated in a multicentre study.

The power of light chain immunoglobulin immunostaining for identifying small monoclonal populations in bone marrow biopsies is illustrated in this study examination of H\&E sections alone had provided little help towards diagnosis in 12 patients in whom light chain staining established the presence of monoclonal plasma cells. This is not an original finding but light chain immunoglobulin immunostaining of bone marrow sections is not yet routine practice for establishing or excluding low volume or minimal disease. Failure to demonstrate monoclonal populations in three patients shows that even smaller diffuse monoclonal populations may not be sufficient to change $\kappa / \lambda$ ratios and therefore they escape detection or else that the disease is nodular as in one patient - and not in the biopsy. We also recognise the fact that polyclonal plasma cells of the same light chain type will be included in the 'monoclonal' plasma cell counts, the proportion becoming less as the monoclonal population increases.

The provision of absolute counts $/ \mathrm{mm}^{2}$ of monoclonal plasma cells is independent of the state of the other bone marrow constituents - unlike percentages which are influenced by the presence of hypoplasia, normoplasia or hyperplasia of the other elements or by the presence of fibrosis causing the aspirated sample to be non-representative. There is already evidence in the literature showing that \% plasma cells in aspirates correlates poorly with the plasma cell content of biopsies [5] and our study adds to this evidence. Yet \% counts are still widely used for aiding differentiation between 
(a)
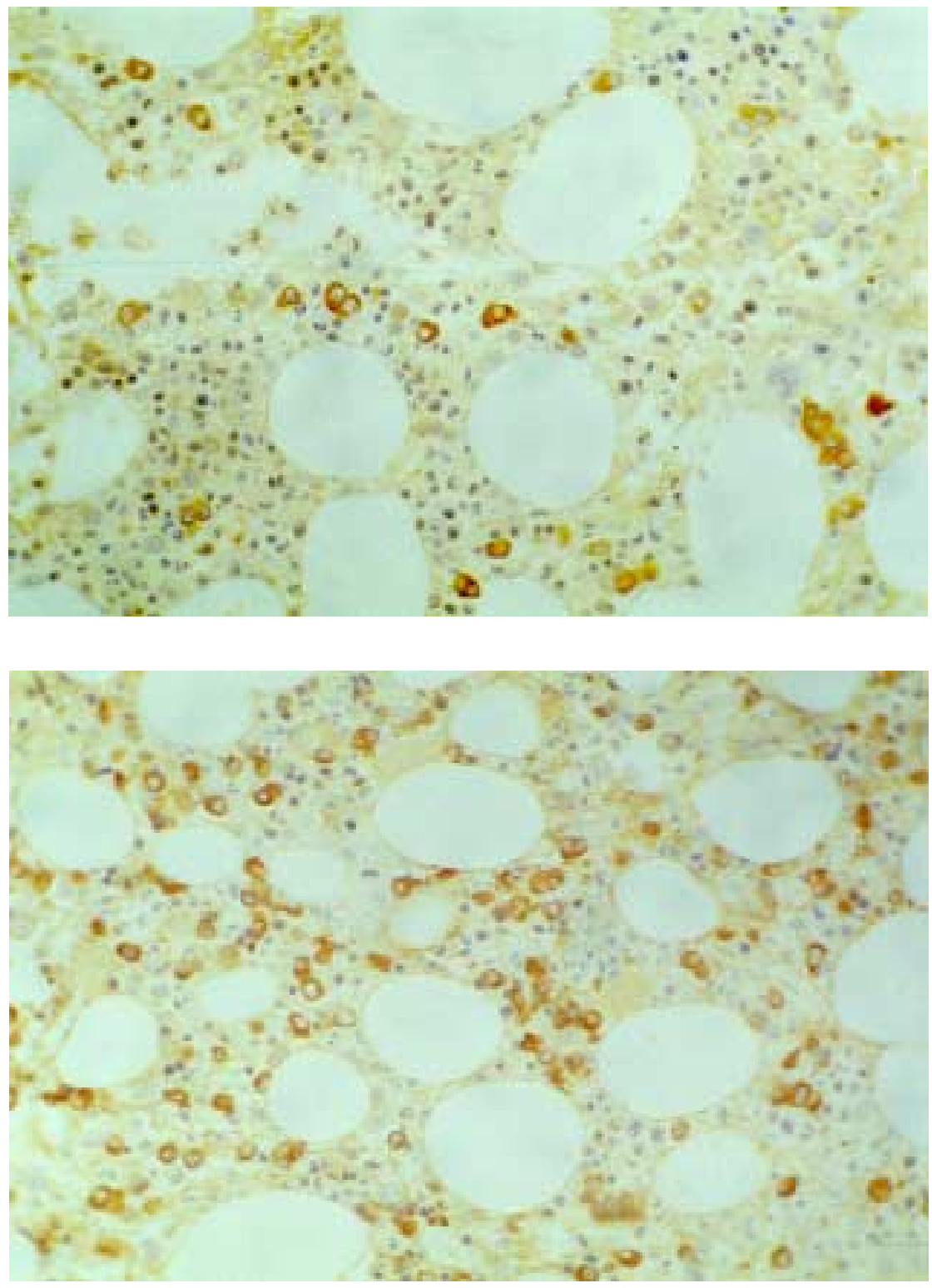

Fig. 2. Photomicrographs of immunostained sections comparing the monoclonal populations of two patients each of whom had $9 \%$ plasma cells in their aspirated samples. Patient $\mathrm{a}-130 / \mathrm{mm}^{2}$ and Patient $\mathrm{b}-908 / \mathrm{mm}^{2}$. This figure can be viewed on http://www.esacp.org/acp/2003/ 25-4/markey.htm

MGUS and MM (and indeed between smoldering, indolent and progressive MM). We suggest that absolute plasma cells $/ \mathrm{mm}^{2}$ bone marrow is a more satisfactory criterion.

This relatively crude procedure provided data which proved retrospectively to be clinically meaningful even in a small study. Importantly, the procedure can be carried out in any routine haematology/histopathology laboratory. Provision of the parameter i.e. absolute monoclonal plasma cells $/ \mathrm{mm}^{2}$ would enable descrip- tive terminology such as moderate, small and minimal plasma cell increase to be discarded and would be helpful in producing interlaboratory conformity of reports.

\section{References}

[1] R. Bartl, B. Frisch, A. Fateh-Moghadam, G. Kettner, K. Jaeger and W. Sommerfeld, Histological classification and staging of multiple myeloma: a retrospective and prospective study of 674 cases, Am. J. Clin. Pathol. 87 (1987), 342-355. 
[2] J. Thiele, B. Arenz, H. Klein, M. Vierbuchen, R. Zankovich and R. Fischer, Differentiation of plasma cell infiltrates in the bone marrow, Virchows Archiv A 412 (1988), 553-562.

[3] B.G. Durie, Staging and kinetics of multiple myeloma, Sem. Oncol. 13 (1986), 300-309.

[4] G.M. Markey, N. Connolly, T.C.M. Morris, P. Kettle and H. Foster, Plasma cell subtypes in bone marrow biopsies from patients without plasma cell dyscrasia, Br. J. Haematol. 114 (2001), 958959.

[5] W.E. Terpstra, H.M. Lokhorst, F.M. Blomjous, O.J.A.Th. Meuwissen and A.W. Dekker, Comparison of plasma cell infiltration in bone marrow biopsies and aspirates in patients with multiple myeloma, Br. J. Haematol. 82 (1992), 46-49. 


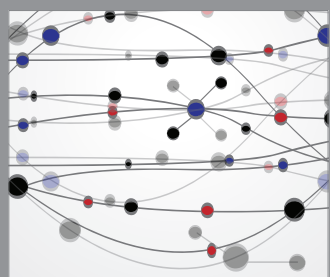

The Scientific World Journal
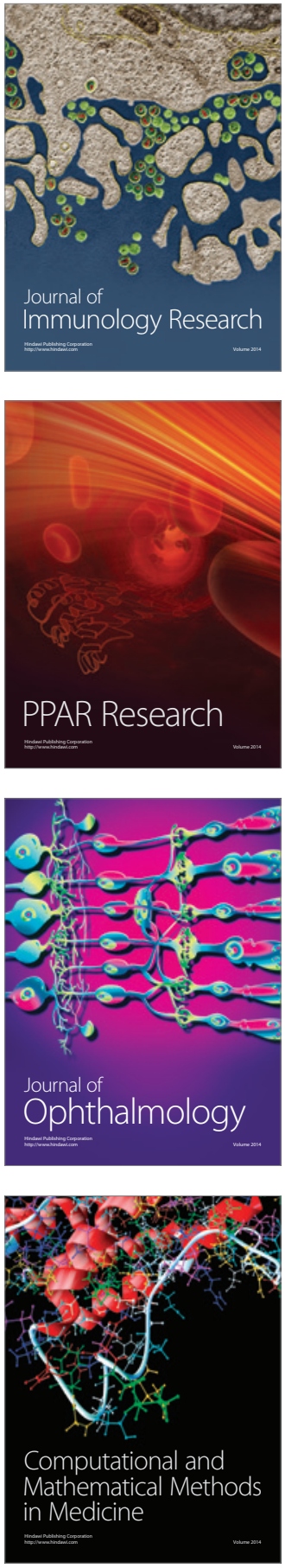

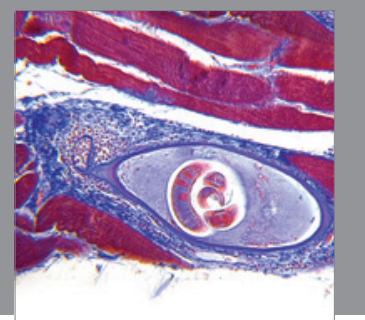

Gastroenterology

Research and Practice
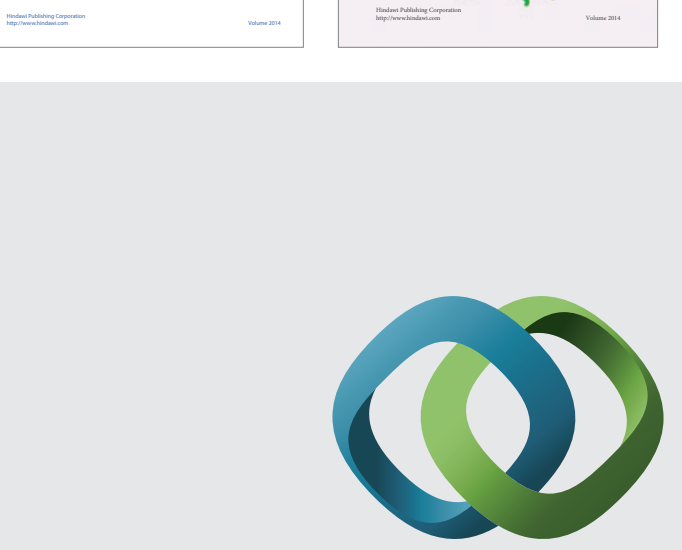

\section{Hindawi}

Submit your manuscripts at

http://www.hindawi.com
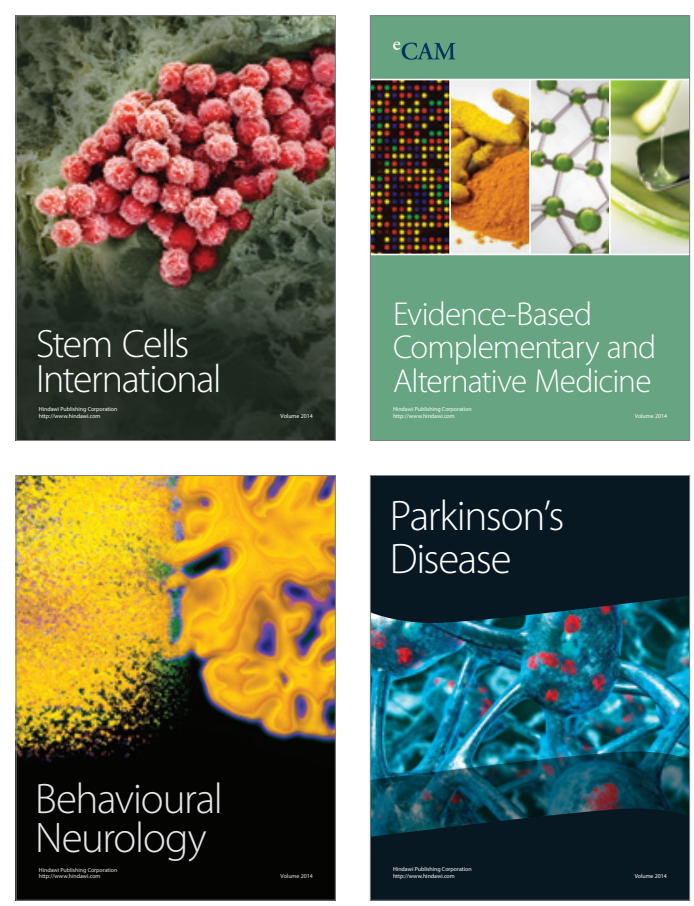

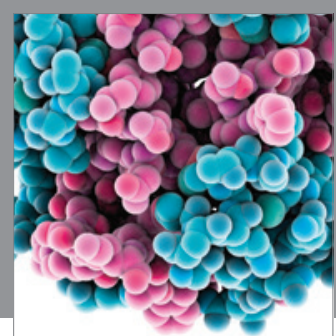

Journal of
Diabetes Research

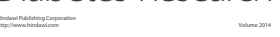

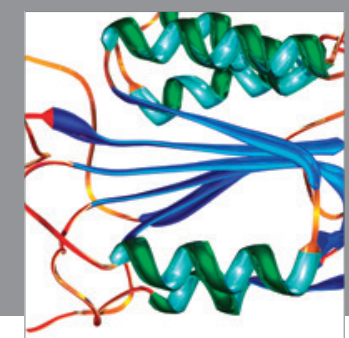

Disease Markers
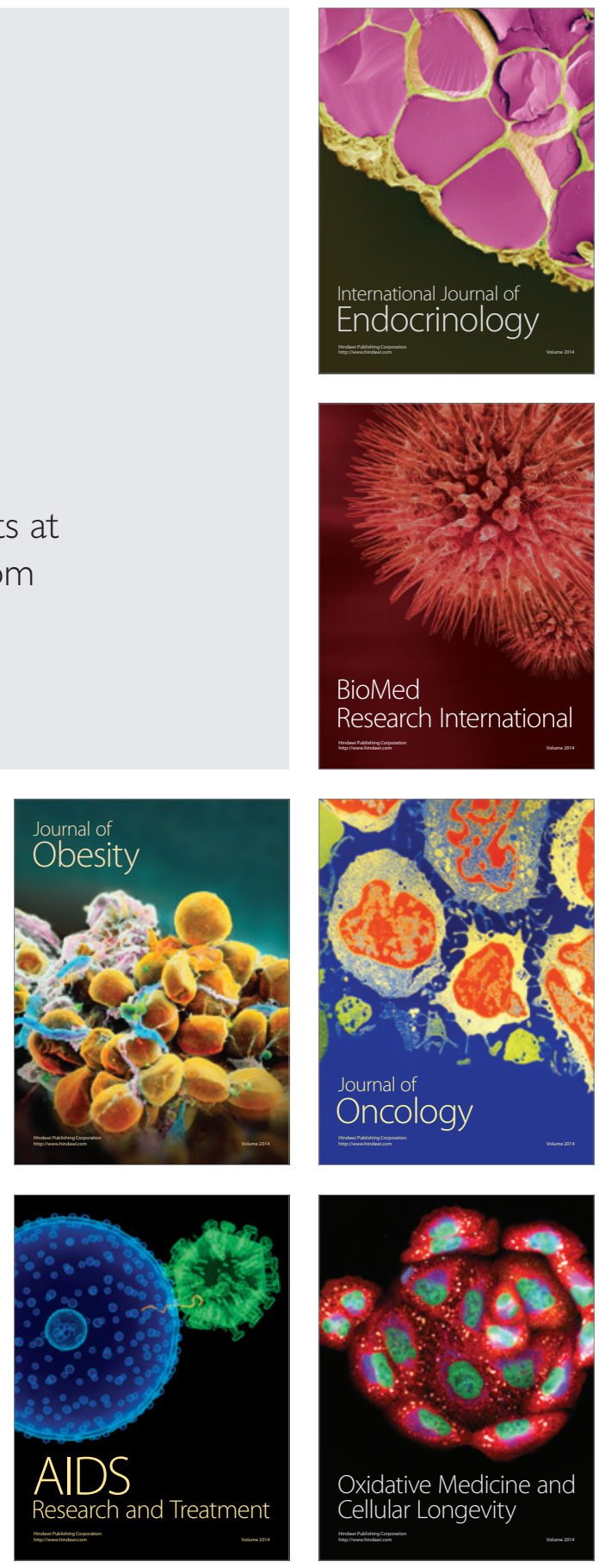